\title{
Work instability and associated factors among patients with rheumatoid arthritis in Greater Poland
}

\author{
Wiktor Schmidt ${ }^{1,2}$, Małgorzata Tąpolska ${ }^{3}$, Katarzyna Pawlak-Buśs ${ }^{1,2}$, Magdalena Owczarek², \\ Piotr Leszczyński ${ }^{1,2}$
}

${ }^{1}$ Department of Rheumatology and Rehabilitation, Poznań University of Medical Sciences, Poland 2Department of Rheumatology and Osteoporosis, J. Struś Municipal Hospital in Poznań, Poland

${ }^{3}$ Department of Public Health, Poznań University of Medical Sciences, Poland

\begin{abstract}
Objectives: Rheumatoid arthritis (RA) affects patients' capacity to work. The Rheumatoid Arthritis Work Instability Scale (RA-WIS) is a reliable method to measure work instability (WI) (1-3). We lack data on the relationship between RA and work instability among Polish patients. Our study aimed to assess WI and associated factors among patients with RA.

Material and methods: The authors conducted a multi-centre cross-sectional observational study. 315 patients from three rheumatology centres were enrolled and filled in questionnaires, including demographic and self-reported clinical data, RA-WIS, and the Health Assessment Questionnaire (HAQ). Swollen and tender joint counts (SJC, TJC) were assessed by the attending physician, and current erythrocyte sedimentation rate (ESR) and C-reactive protein (CRP) were collected. We excluded 41 patients due to an incorrectly filled in form and analysed questionnaires of 274 patients. DAS28 (Disease Activity Score in 28 joints) and DAS28-CRP were calculated. We performed statistical analysis with Statistica v. 13.3 using the Mann-Whitney $U$ test, $\chi^{2}$ test, and Spearman's correlation. Results: 140 (51\%) patients were currently employed and their characteristics were analysed. In univariable analysis we identified the following risk factors for high risk WI: moderate-to-high disease activity (DAS28 $\geq 3.2-$ OR 2.29, 95\% Cl 1.06-4.96, $p=0.033$; DAS28-CRP $\geq 3.2-$ OR 2.34, 95\% $\mathrm{Cl} 1.04-5.27, p=0.038)$, ESR $\geq 30 \mathrm{~mm} / \mathrm{h}$ in women and $\geq 20 \mathrm{~mm} / \mathrm{h}$ in men (OR 2.65, 95\% Cl 1.205.89, $p=0.010$ ), CRP $\geq 1 \mathrm{mg} / \mathrm{dl}$ (OR 4.02, 95\% Cl 1.78-9.10, $p<0.001$ ), HAQ-DI > 1.0 (OR 2.23, 95\% $\mathrm{Cl} 1.04-4.81, p=0.037$ ) and at least moderate pain on the visual analogue scale (VAS $p \geq 4.5 \mathrm{~cm}-\mathrm{OR}$ 5.31, 95\% Cl 2.36-11.96, $p<0.001)$.

Correlations were moderate between RA-WIS and VASp (RS $=0.59, p<0.001$ ) and HAQ-DI (RS $=0.52, p<0.001$ ) but weak with disease activity indices (DAS28 [RS $=0.31, p<0.001]$; DAS28CRP $[R S=0.28, p<0.001])$.

Conclusions: Pain and disability are the main factors strongly associated with work instability among patients with RA.
\end{abstract}

Key words: rheumatoid arthritis, arthritis, work instability, work disability.

\section{Introduction}

Rheumatoid arthritis (RA) is a chronic inflammatory disease that develops predominantly in middle-aged people, affecting their quality of life and capacity to work. Disability linked to articular damage affects both patients' and public healthcare systems' economic status through work absence and productivity loss [1, 2]. In recent years many new therapies have been introduced into the management of RA, including synthetic (Janus kinase inhibitors) and biologic or biosimilar therapies such as agents against tumour necrosis factor

Address for correspondence:

Wiktor Schmidt, Department of Rheumatology and Rehabilitation, Poznań University of Medical Sciences, $135 / 13728$ czerwca 1956 r. St. 61-545 Poznań, Poland, e-mail: wiktorpawelschmidt@gmail.com

Submitted: 15.06.2020; Accepted: 4.08.2020 
(anti-TNFs), interleukin-6 receptor (anti-IL-6R) and cluster of differentiation 20 (anti-CD20). Access to the novel treatment is unequal and varies greatly between different countries, ranging from 2 to $75 \%$ of patients [3].

A number of studies from all over the world have assessed work instability in patients with rheumatoid arthritis and associated factors [4-7]. The Rheumatoid Arthritis Work Instability Scale (RA-WIS) is a reliable method to measure work instability that has been translated into many languages and cross-culturally validated [8-10].

Data on the topic of the relationship between rheumatoid arthritis and work instability among Polish patients is lacking. We conducted this study to assess that problem in three rheumatology centres and investigate whether work instability is linked to factors such as current disease activity, disease duration, the time between symptoms onset and treatment initiation, current and past medications, socioeconomic status, pain and disability.

The abstract of this research was presented at European League Against Rheumatism (EULAR) e-Congress 2020 [11].

\section{Material and methods}

\section{Study design, setting and patients}

The authors conducted an observational cross-sectional multi-centre study from January 31, 2017, to October 31, 2019, in three rheumatology centres from Greater Poland Voivodeship (two in Poznań, one in Śrem). Enrolled patients fulfilled RA 2010 ACR/EULAR classification criteria [12]. The majority of patients were female $(n=111,79.3 \%)$ with a mean $( \pm$ SD) age of $48.7( \pm 11.0)$ years and with longstanding disease (defined as lasting $>5$ years from the diagnosis, $n=114,81.4 \%$ ). During the visit, after receiving consent from the patient, the attending physician completed the first part of an anonymized form based on patient medical history and laboratory results, then the patient filled in the second part of the anonymous questionnaire.

The local ethical committee of Poznań University of Medical Sciences opinion of the non-experimental character of our research was obtained.

\section{Physician assessment}

Treating physicians collected clinical and laboratory data using a standardized form. The following information was obtained: tender and swollen joint count in 28 joints, disease activity assessed by the physician via Visual Analogue Scale (VAS 0-10 cm), erythrocyte sedimentation rate (ESR), C-reactive protein (CRP) concen- tration, presence of rheumatoid factor (RF) and/or anticitrullinated peptide antibody (ACPA). Disease Activity Score in 28 joints (DAS28) and DAS28-CRP were calculated and the following thresholds were used: < 2.6 for remission, 2.6-3.19 for low activity, 3.2-5.1 for moderate activity and $>5.1$ for high activity $[13,14]$.

\section{Patient-reported outcome measures}

All patients filled in a form that included socio-demographic data (age, gender), current work status, RA history (disease duration from onset of symptoms and from diagnosis, number of flares in last 6 months) and treatment (current and previous), smoking status, comorbidities (diabetes, arterial hypertension, ischaemic heart disease including past myocardial infarction, asthma, chronic obstructive pulmonary disease, gastroesophageal reflux disease, peptic ulcer disease, chronic kidney disease, hypothyroidism, neoplasms, osteoporosis, depression, anxiety disorder) and familial history of RA or other rheumatic conditions.

The questionnaire was prepared for this research. Each enrolled patient also completed Polish versions of validated HAQ-DI and RA-WIS forms [8, 10, 15, 16]. Patients with $>17$ in RA-WIS were considered to have high work instability, scores of 10-17 were treated as moderate work instability, whereas scores $<10$ were treated as low [8].

\section{Statistical analysis}

The authors performed all statistical calculations with Statistica v.13.3. We used descriptive statistics to describe the studied population and conducted a univariable analysis using the $\chi^{2}$ test for comparison of categorical data and the Mann-Whitney $U$ test for continuous data without normal distribution. Spearman's rank correlation coefficient was calculated to assess the correlation between monotonic relationships between variables. We defined the correlation strength as weak for Spearman's rank correlation coefficient 0.2-0.4, moderate for 0.4-0.6.

\section{Results}

The 315 patients were enrolled. The authors excluded 41 patients due to an incorrectly filled form and analysed questionnaires of 274 patients. The 140 (51\%) patients were currently employed and their characteristics are presented in Table I.

Overall mean $( \pm \mathrm{SD})$ disease duration was $11.6( \pm 8.5)$ years. Most of them had at least moderate disease activity (DAS28 > 3.2, $n=86,61.4 \%$ ) and were seropositive $(n=107,76.4 \%)$ in rheumatoid factor in IgM class 
( $n=102,72.9 \%)$ and/or anti-citrullinated peptide antibodies ( $n=88,62.9 \%)$.

Most patients were treated with conventional synthetical disease-modifying antirheumatic drugs (cSDMARDs, $n=135,96.4 \%)$, mainly oral methotrexate ( $n=84,60 \%)$ and leflunomide $(n=47,33.6 \%) .42(30 \%)$ patients currently received biologic agents, mainly antiIL-6R $(n=20,14.3 \%)$ and anti-TNF ( $n=18,12.9 \%)$. $69(49.3 \%)$ patients received more than one DMARD at the time of filling in the form. Glucocorticoids (GCS) were taken on a daily basis by 61 (43.5\%) patients, 18 $(12.9 \%)$ patients were prescribed with them during flares, whereas 28 (20\%) received them in a short period after diagnosis as bridging therapy. The 29 (20.7\%) patients had never been administered GCS. The 49 (35\%) patients used analgesics (mainly non-steroidal antiinflammatory drugs, NSAIDs) every day, while 87 (62.1\%) used them only during flares.

The mean $( \pm$ SD) HAQ-DI score was $0.80( \pm 0.54)$ and 39 (27.9\%) of patients had a HAQ-DI index of at least 1 , indicating functional disability. The mean RA-WIS ( \pm SD) score was $13.45( \pm 6.14)$. The $46(32.9 \%)$ patients had high work instability. They differed significantly from patients with low-to-moderate work instability in ESR, CRP, tender and swollen joint count (TJC and SJC, respectively), HAQ-DI, pain on VAS scale and disease activity measured with DAS28 and DAS28-CRP - as shown in Table I.

In the univariable analysis we identified the following risk factors for high risk WI: at least moderate pain on the Visual Analogue Scale (VASp $\geq 4.5 \mathrm{~cm}$ ), prolonged $E S R$, elevated CRP, moderate-to-high disease activity (defined as DAS28 $\geq 3.2$ or DAS28-CRP $\geq 3.2$ ) and disability defined as HAQ-DI > 1.0 - as presented in Table II.

Correlations were moderate between RA-WIS and VASp (RS $=0.59, p<0.001)$ and HAQ-DI (RS = 0.52, $p<0.001$ ) but weak with disease activity indices (DAS28 [RS $=0.31, p<0.001]$; DAS28-CRP [RS $=0.28, p<0.001]$ ).

\section{Discussion}

Rheumatoid arthritis is associated with functional disability, stress, fatigue and chronic pain. All these factors affect patients' capacity to work and lead to increased work absence and productivity loss, which has a significant effect on the costs for patients, employers and healthcare providers [17-19]. Prevention of work loss is crucial for patients, as it affects their finances, health, and functioning in society. Financial loss linked directly with sick leave and indirectly with a decrease in production and recruitment of new employees can be reduced by early identification, diagnosis and treatment of patients with rheumatoid arthritis [20, 21]. Early administration of DMARDs in the treat-to-target approach
Table I. Demographic and clinical characteristics of employed patients according to work instability risk, $n$ (\%) or mean $( \pm S D)$

\begin{tabular}{|lcc|}
\hline Characteristic & \multicolumn{2}{c|}{ RA-WIS score } \\
\cline { 2 - 3 } & $\begin{array}{c}\text { Low-to-moderate } \\
(0-17)\end{array}$ & High $(>17)$ \\
\hline Patients & $94(67.1)$ & $46(32.9)$ \\
\hline Gender, female & $73(77.7)$ & $38(82.6)$ \\
\hline Age (years) & $47.9( \pm 11.8)$ & $50.4( \pm 9.3)$ \\
\hline Disease duration (years) & $13.0( \pm 8.4)$ & $14.0( \pm 8.7)$ \\
\hline RF, positive & $68(72.3)$ & $34(73.9)$ \\
\hline ACPA, positive & $59(62.8)$ & $29(63.0)$ \\
\hline ESR (mm/h) & $18.3( \pm 16.0)$ & $28.2( \pm 21.9)^{\star}$ \\
\hline CRP $(m g / d l)$ & $0.6( \pm 1.0)$ & $1.1( \pm 1.0)^{\star}$ \\
\hline TJC & $4.5( \pm 4.0)$ & $7.6( \pm 6.3)^{\star}$ \\
\hline SJC & $2.7( \pm 3.0)$ & $5.2( \pm 5.5)^{\star}$ \\
\hline HAQ-DI & $0.7( \pm 0.5)$ & $1.1( \pm 0.5)^{\star}$ \\
\hline Pain - VAS 10 cm & $3.9( \pm 1.9)$ & $6.5( \pm 2.2)^{\star}$ \\
\hline DAS28 & $3.5( \pm 1.2)$ & $4.2( \pm 1.4)^{\star}$ \\
\hline DAS28-CRP & $3.9( \pm 1.0)$ & $4.3( \pm 1.2)^{\star}$ \\
\hline
\end{tabular}

WI - work instability, RA-WIS - Rheumatoid Arthritis Work Instability Scale, RF-rheumatoid factor in IgM class, ACPA - anti-citrullinated protein antibodies, ESR - erythrocyte sedimentation rate, $C R P-C$-reactive protein, $T J C$-tender joint count, SJC-swollen joint count, HAQ-DI - Health Assessment Questionnaire Disability Index, VAS - Visual Analogue Scale, DAS28 - Disease Activity Score in 28 joints, ${ }^{*} p<0.05$, Mann-Whitney $U$ test.

Table II. Factors associated with high work instability

\begin{tabular}{|lccc|}
\hline Factor & $\begin{array}{c}\text { Odds ratio } \\
(\mathrm{OR})\end{array}$ & $\begin{array}{c}\text { 95\% confidence } \\
\text { interval }(\mathrm{Cl})\end{array}$ & $\begin{array}{c}p \text {-value } \\
\left(\chi^{2} \text { test }\right)\end{array}$ \\
\hline Pain VAS $\geq 4.5 \mathrm{~cm}$ & 5.31 & $2.36-11.96$ & $<0.001$ \\
\hline CRP $\geq 1 \mathrm{mg} / \mathrm{dl}$ & 4.02 & $1.78-9.10$ & $<0.001$ \\
\hline Prolonged ESR & 2.65 & $1.20-5.89$ & 0.010 \\
\hline DAS28-CRP $\geq 3.2$ & 2.34 & $1.04-5.27$ & 0.038 \\
\hline DAS28 $\geq 3.2$ & 2.29 & $1.06-4.96$ & 0.033 \\
\hline HAQ-DI $>1.0$ & 2.23 & $1.04-4.81$ & 0.037 \\
\hline
\end{tabular}

DAS28 - Disease Activity Score in 28 joints, ESR - erythrocyte sedimentation rate, CRP - C-reactive protein, HAQ-DI - Health Assessment Questionnaire Disability Index, VAS - Visual Analogue Scale, * defined as ESR $\geq 30 \mathrm{~mm} / \mathrm{h}$ in women and $\geq 20 \mathrm{~mm} / \mathrm{h}$ in men.

is associated with a lesser burden of articular damage and disability (citation).

Job retention among patients with rheumatoid arthritis should be maximized, and this can be achieved not only by early diagnosis but also by identifying risk factors of high work instability. Therefore, physicians should pay attention to those at risk of work loss to make an appropriate intervention. 
In our study we found that $32.9 \%$ of currently employed patients had high risk of work instability. We found that pain was the strongest risk factor, followed by elevated acute phase reactants, at least moderate disease activity and disability. We observed a moderate correlation between RA-WIS score and both pain on VAS scale and HAQ-DI index, whereas the correlation between RA-WIS score and disease activity was weak. Our findings are consistent with previous studies on this subject.

Macedo et al. [7] found that RA-WIS correlates with HAQ and DAS-28, but not with age or disease duration, which is consistent with our results. We also found a correlation between pain on VAS scale and RA-WIS. Our results showed that RA-WIS correlated more strongly with HAQ-DI than disease activity (DAS28 and DAS28 (RP), which reflects previous findings suggesting that work instability is associated more strongly with pain and functional scores than indices of disease activity [7].

According to Revicki et al. [9], who tested the reliability and validity of the Work Instability Scale for Rheumatoid Arthritis, RA-WIS correlates with HAQ-DI, DAS-28, and patient assessment of pain, which was also confirmed in our investigation.

Further research needs to be conducted on the subject of RA treatment and work instability. In our study we did not find differences between patients receiving biological DMARDs and those receiving CSDMARDs. It has to be emphasised that the cross-sectional design of the study could contribute to such findings. Moreover, access to biologic therapy in Poland is limited compared to most European countries and patients with more active and aggressive disease receive it, often after functional disability has already occurred [3]. More data on treatment influence on work instability will be available in the near future as RA-WIS is being used as a secondary outcome in some clinical trials [22-24].

Several limitations of our study should be noted. Firstly, we used the RA-WIS Polish version, which has not been validated. Secondly, data considering the type of work performed by the patients were not collected. Furthermore, we did not analyse variables of working environment characteristics or employee support, which may also have affected RA-WIS score. However, it was found that RA-WIS did not differ significantly between two occupation categories (white collar or blue collar) among patients in the United Kingdom [7].

\section{Conclusions}

Pain and disability are the main factors associated with work instability. Early intervention of proper therapy to prevent disease damage and optimise pain management can lead to better job retention among patients with RA.

\section{Acknowledgments}

Special thanks to Wojciech Romanowski of Poznań Centre of Rheumatology, Śrem, Poland and Marek Rabski of the Department of Rheumatology and Rehabilitation, Medical University in Poznań, Poznań, Poland for support in collecting data.

The authors declare no conflict of interest.

\section{References}

1. Verstappen SMM, Bijlsma JWJ, Verkleij H, et al. Overview of work disability in rheumatoid arthritis patients as observed in cross-sectional and longitudinal surveys. Arthritis Rheum 2004; 51:488-497, DOI:10.1002/art.20419.

2. Shanahan EM, Smith MD. Rheumatoid arthritis, disability and the workplace. Baillieres Best Pract Res Clin Rheumatol 1999; 13: 675-688, DOI:10.1053/berh.1999.0053.

3. Putrik P, Ramiro S, Kvien TK, et al. Inequities in access to biologic and synthetic DMARDs across 46 European countries. Ann Rheum Dis 2014; 73: 198-206, DOI:10.1136/annrheumdis-2012-202603.

4. Tamborenea MN, Pisoni C, Toloza S, et al. Work instability in rheumatoid arthritis patients from Argentina: prevalence and associated factors. Rheumatol Int 2015; 35: 107-114, DOI:10.1007/s00296-014-3062-7.

5. Looper KJ, Mustafa SS, Zelkowitz P, et al. Early Arthritis Research Group. Work instability and financial loss in early inflammatory arthritis. Int J Rheum Dis 2012; 15: 546-553, DOI:10.1111/1756-185X.12009.

6. Tang K, Canadian Arthritis Network Work Productivity Group. Disease-related differential item functioning in the work instability scale for rheumatoid arthritis: converging results from three methods. Arthritis Care Res (Hoboken) 2011; 63: 1159-1169, DOI:10.1002/acr.20491.

7. Macedo A, Oakley S, Gullick N, Kirkham B. An examination of work instability, functional impairment, and disease activity in employed patients with rheumatoid arthritis. J Rheumatol 2009; 36: 225-230, DOI:10.3899/jrheum.071001.

8. Gilworth G, Chamberlain MA, Harvey A, et al. Development of a work instability scale for rheumatoid arthritis. Arthritis Rheum 2003; 49: 349-354, DOI:10.1002/art.11114.

9. Revicki D, Ganguli A, Kimel M, et al. Reliability and Validity of the Work Instability Scale for Rheumatoid Arthritis. Value Health 2015; 18: 1008-1015, DOI:10.1016/j.jval.2015.09.2941.

10. Gilworth G, Emery P, Gossec L, et al. Adaptation and cross-cultural validation of the rheumatoid arthritis work instability scale (RA-WIS). Ann Rheum Dis 2009; 68: 1686-1690, DOI:10.1136/ard.2008.098921.

11. Schmidt W, Tapolska M, Owczarek M, et al. Work instability among Polish rheumatoid arthritis patients. Ann Rheum Dis 2020; 79 (Suppl 1): 1883. 
12. Kay J, Upchurch KS. ACR/EULAR 2010 rheumatoid arthritis classification criteria. Rheumatology (Oxford) 2012; 51 Suppl 6 : vi5-9, DOI:10.1093/rheumatology/kes279.

13. Inoue E, Yamanaka H, Hara $\mathrm{M}, \mathrm{t}$ al. Comparison of Disease Activity Score (DAS)28 - erythrocyte sedimentation rate and DAS28-C-reactive protein threshold values. Ann Rheum Dis 2007; 66: 407-409, DOI:10.1136/ard.2006.054205.

14. van der Heijde DM, van't Hof MA, van Riel PL, et al. Judging disease activity in clinical practice in rheumatoid arthritis: first step in the development of a disease activity score. Ann Rheum Dis 1990; 49: 916-920, DOI:10.1136/ard.49.11.916.

15. Fries JF, Spitz P, Kraines RG, Holman HR. Measurement of patient outcome in arthritis. Arthritis Rheum 1980; 23: 137-145, DOI:10.1002/art.1780230202.

16. Bruce B, Fries JF. The Health Assessment Questionnaire (HAQ) Clin Exp Rheumatol 2005; 23 (5 Suppl 39): S14-18.

17. Kvien TK. Epidemiology of disability in rheumatoid arthritis. Rheumatology (Oxford) 2002; 41: 121-123, DOI:10.1093/rheumatology/41.2.121.

18. Geuskens GA, Hazes JMW, Barendregt PJ, Burdorf A. Work and sick leave among patients with early inflammatory joint conditions. Arthritis Rheum 2008; 59: 1458-1466, DOI:10.1002/ art.24104.

19. Gignac MAM, Cao X, Lacaille D, et al. Arthritis-related work transitions: A prospective analysis of reported productivity losses, work changes, and leaving the labor force. Arthritis Care Res 2008; 59: 1805-1813, DOI:10.1002/art.24085.
20. Barrett EM, Scott DG, Wiles NJ, Symmons DP. The impact of rheumatoid arthritis on employment status in the early years of disease: a UK community-based study. Rheumatology (Oxford) 2000; 39: 1403-1409, DOI:10.1093/rheumatology/39.12.1403.

21. Eberhardt K. Very early intervention is crucial to improve work outcome in patients with rheumatoid arthritis. J Rheumatol 2009; 36: 1104-1106, DOI: 10.3899/jrheum.090174.

22. AbbVie. A Phase 2b/3, Randomized, Double-Blind Study Comparing Upadacitinib (ABT-494) to Placebo in Japanese Subjects With Moderately to Severely Active Rheumatoid Arthritis Who Are on a Stable Dose of Conventional Synthetic Disease-Modifying Anti-Rheumatic Drugs (CsDMARDs) and Have an Inadequate Response to CsDMARDs. clinicaltrials.gov; 2020. https:// clinicaltrials.gov/ct2/show/NCT02720523 (access: 22.05.2020).

23. AbbVie. Progress at Work - The Impact of Adalimumab on Work Related Productivity in Patients With Rheumatoid Arthritis. clinicaltrials.gov; 2020. https://clinicaltrials.gov/ct2/ show/NCT02362074 (access: 22.05.2020).

24. Hoffmann-La Roche. TOSCARA: An Open-Label, Single Arm Study to Evaluate the Efficacy, Safety and Tolerability of Tocilizumab (TCZ) Subcutaneous in TCZ-Naïve Patients With Active Rheumatoid Arthritis. clinicaltrials.gov; 2017. https://clinicaltrials.gov/ct2/show/NCT02031471 (access: 22.05.2020). 